Session 2555

\title{
Addressing the Need for Engineering Educators in Higher Education: A Proposal and an Associated Curriculum
}

\author{
Eugene J. Audette, Ph.D., L.P. \\ Associate Dean, Academics \& Research \\ School of Education \\ University of St. Thomas-Minneapolis
}

\author{
Ronald J. Bennett, Ph.D. \\ Director and Chair \\ School of Engineering \& Technology Management \\ University of St. Thomas-St. Paul
}

Thesis: To ensure a well-prepared engineering force to contribute to the U.S. economy, higher education needs to prepare a new cadre of faculty who are experts in the theories, processes and practices of engineering as well as higher education to replace the anticipated retirements from the engineering professoriate and to enhance the present engineering professoriate.

\section{The Need}

In his Distinguished Lecture presentation at the 2003 ASEE Annual Conference, Dr. Joseph Bordogna made the statement "Engineers ride the crest of the wave and arrive first at new shores." The importance of the role of engineers to society is underestimated and, even though engineers are very productive and the leverage of their work is great, we are experiencing a decline in the number of students in graduate engineering programs and a flat number of engineers graduating from undergraduate programs. This is of significant global importance since the rest of the world is producing engineers at much higher rates. In Europe and Asia, a far greater percentage of university students are enrolled in engineering education. That may partially explain why so many manufacturing jobs are moving overseas.

What is the cause of this low level of interest in engineering in the United States? There are many possible causes, but one seems to clearly relate to the lack of compelling engineering courses taught by faculty who have extensive experience in the profession. As noted by Dr. 
Bordogna, "engineering education must change." The strict compartmentalization of scholarly topics that has been the hallmark of advanced education of all sorts must change. "Nature doesn't know disciplinary boundaries" notes Dr. Bordogna. We need to make changes that will significantly increase the relevance and holistic nature of engineering education. While there is still a need for basic research programs in engineering colleges, there is a growing need for engineering programs that focus on applications. These programs must of course be academically sound and rigorous. We must simply expand the definitions of scholarship to that of Boyer-the scholarship of discovery, integration, application and teaching (Boyer, 1990). This kind of scholarship is what played such a positive role in the growth and development of both engineering and business in the earlier part of the $20^{\text {th }}$ century. We need to develop holistic, interdisciplinary academic programs that will produce engineers with the technical skills, passion and courage to make a difference. These programs must create excitement about engineering. Developing excellent teachers from our experienced engineers can do this best, individuals who bring to the classroom a wealth of experience, the vision of emerging opportunities from the laboratory and who can be credible liaisons between industry and the academy.

Dr. William Wulf, president of the National Academy of Engineering, predicts that we will need a million entry-level engineers in the next decade. Colleges in the United States are producing 65,000 engineers each year-just two-thirds of that rate. Factor in the retirement of older engineers and the result is a shortage of about 350,000 engineers by 2012.

Traditionally, new full-time professors of engineering, much like new collegiate faculty in other disciplines, enter the professoriate early in their careers after a graduate program of study that leads to the Ph.D. Such programs tend to emphasize theoretical and applied research to advance the profession's knowledge base. But the field of engineering is seeing few new engineers choosing postgraduate study to prepare to be engineering faculty, drawn as they are towards (usually) higher pay employment opportunities in industry and government. Since engineering is a hybrid profession drawing as it does on several academic disciplines to form its theoretical base-e.g. mathematics, physics, computer science, communications, business practice-it aims advanced study at finding solutions to practical problems and through that focus to advance the profession.

The potential weakness of the current model is that the engineering students of these new Ph.D. recipients may not receive the strongest undergraduate education because the research-focused young Ph.D.s may be more interested in building or continuing their research agenda than they are in teaching the next generation of B.S. and/or M.S. level students.

\section{Source for New Engineering Faculty}

We offer a partial remedy to this situation. To address the growing shortage of faculty and to complement the existing $\mathrm{PhD}-$ oriented full-time faculty in U.S. colleges and universities, engineering should find ways to draw on the extensive experience and wisdom of veteran engineers who may be looking for ways to refresh their own careers and at the same time to

fulfill a value and desire common to middle-aged adults-to give back to society and to stay relevant. Multiple career changes for an engineer in industry are now the norm. Many are 
interested in refreshing their own careers and at the same time fulfilling a value and desire common to middle aged adults to share what they know and value with the next generation. Erik Erikson's seminal theory of life-span development identified this desire as "generativity," the $7^{\text {th }}$ stage of adulthood (Coles, 1970; Erikson, 1968; Miller, 1989; Schlein, 1987). Generativity captures the meaning of this midlife desire to positively influence the next generation, and the engineering profession can channel that energy into the engineering higher education arena.

Bennett has called our attention to the potential that career mature engineers can bring to the profession and the nation:

To prepare the next generation of engineers, we need to enlist the help of retiring engineers and promote engineering education from grade school through high school....Retiring engineers...offer tremendous potential. By expanding mentoring programs and providing teaching certification for these engineers to teach math and science in the K-12 systems, they could bring experience and excitement to science education into the schools" (Bennett, 2003).

A similar appeal can and should be made to expand and deepen the faculty pool in higher education. These recruits to the college teaching ranks would be able to satisfy generative values and interests while staying vitally identified with the cutting edge of the profession (Hansen, 1997; Niles, 2002; Super, 1980). The program described herein could be a strong draw for veteran practitioners.

To prepare them for full-time work as teachers of engineering, we propose a doctorate leading to an Ed.D. in Engineering Education. The Ed.D. historically has been a practitioner-focused terminal degree emphasizing theoretically grounded cutting edge practice while not neglecting basic skill in qualitative and quantitative research methodologies. A practice-focused preparation program makes sense when it recruits from the pool of experience-rich veteran engineers who want to refresh their careers and continue to contribute to the field (Niles, 2002).

\section{Resources}

The resources needed to launch such a preparation program exist in many comprehensive universities. What are needed is an engineering program that offers graduate level degree and certificate programs, and a School or College of Education accredited to offer the Ed.D. degree. Having both of these programs in place within one institution would better assure that the requisite courses and faculty are available to jointly offer the degree. A useful complement to these two units would be a College of Business. The alternative approach would be a jointinstitutional model where one college or university has a School of Engineering and a neighboring institution has a School or College of Education. The number of such jointinstitutional cross-discipline programs is increasing nationally as leaders both in the professions and in higher education recognize the need for cross-programmed professionals in our complex society, e.g. JD-MBA, MD-M.Pharm. or MD-MBA, MSW-M.Div., JD-MA in Public Affairs. 


\section{Curriculum}

Higher education teaching requires a set of knowledge bases and competencies distinct from yet compatible with the other university faculty responsibilities of contributing to the knowledge of the disciplines and professions through some form of research and scholarship and consequent writing and professional service. A plausible 59-72 semester credit curriculum for an Ed.D. in Engineering Education could contain learning components in the following five areas:

1. Foundations

2. Pedagogy

3. Instructional Practice

4. Collateral Learning

5. Applied Research

Following a semester-credit model with each course usually being three semester credits in value, the curricular components would provide content and skill derived from study in the five areas. The total credits for the degree could range from $59-70$ credits.

1. Foundations:

The proposed courses would provide an understanding of higher education and of its stakeholders: students, employers, the larger work society in which a professional functions (Bee, 1996; Boyer, 1990; Lachman, 2001; Simonsen, 1997; Tierney, 1991). The course sequence in Foundations could be:

- Historical and Philosophical Foundations of Collegiate Education (3 cr.)

- Developmental Psychology of Adulthood (3 cr.)

- Organizational Theory and Behavior (3cr.)

- Communication and Human Relations in the Workplace $(3 \mathrm{cr}$.)

- Career Development of Professionals in Organizations (3 cr.)

- Candidate Self-Assessment and Personal Planning (Total of 3 credits stranded in 1 -credit increments during the program of study) $(3 \mathrm{cr}$.)

$$
\text { Total }=18 \text { credits }
$$

2. Pedagogy/Androgogy:

The following courses would provide the theoretical and skill bases for teaching in higher Education (Angelo, 1993: Brookfield, 1995; Cranton, 1994; Fink, 2003; Jonassen, 2000; Merriam, 1999; Mezirow, 1991: Schön, 1987). The course sequence in Pedagogy/Androgogy could be:

- Adult Learning and Instruction: Theories, Models and Processes $(3 \mathrm{cr}$.)

- Psychology of Cognition and Learning $(3 \mathrm{cr}$.)

- Design of Instruction Systems (3 cr.)

- Assessment and Evaluation of Learning (3 cr.)

- Management of Instructional Systems (2-3 cr.)

- Instructional Technology (including web-assisted and web-based instruction) (3-4 cr.)

$$
\text { Total }=17-19 \text { credits }
$$


3. Instructional Practice:

These courses would provide hands-on and critiqued experience in instructional processes in a variety of settings e.g. traditional classroom, distance learning modes (Brookfield, 1990; Brookfield, 1999; Halpern, 1994; Knowles, 1986). A course sequence could be:

- Guided Clinical Observation of Higher Education Instruction (2 cr.)

- Practice Teaching ( 6 credits over 2 semesters)

- co-teach an undergraduate Engineering course paired with an experienced professor. (2 cr.)

- design and solo teach an undergraduate or graduate engineering course with a parallel proseminar for guidance exchange and formative assessment with other candidates and experienced faculty. (6 cr.)

$$
\text { Total }=10 \text { credits }
$$

\section{Collateral Engineering Coursework}

This component would encourage the veteran engineer, with guidance and consent of the advisor, to refresh or deepen the candidate's current engineering background or pursuit of a new specialty to broaden one's cognate background.

- graduate engineering courses (6-12 credits)

5. Applied Research: the dissertation

The Ed.D. dissertation experience challenges the degree candidates to contribute to the body of knowledge and practice in engineering education and thereby demonstrate their potential as contributing researchers and future faculty members in higher education.

- writing the proposal ( $3 \mathrm{cr}$.)

- dissertation

(6-9 cr.)

$$
\text { Total }=9-12 \text { credits }
$$

Total cumulative credits $=59-72$ credits

A cohort model of study would provide the ideal delivery vehicle for such a doctoral program. Cohort models of degree completion in higher education have several advantages that have been demonstrated in other practitioner-focused Ed.D. programs nationwide. Because all members of a cohort begin at the same time and the members take most or all of their courses in common during phases 1-3 of the program of study that we propose, a strong and lasting professional bond develops among the members. This bond usually is maintained after the members of the cohort graduate and this bond develops a network for ongoing professional consultation, support and future partnered endeavors. Also, the cohort model has demonstrated a much higher graduation rate than the more traditional approach to doctoral preparation in American higher education where each $\mathrm{ABD}$ walks virtually alone on their path to the terminal degree realizing less than $50 \%$ completion rate. Finally, the cohort model is ideal for working professionals or professionals in transition because it works well with a part-time yet intense approach to doctoral study. It can result in $80 \%$ graduation rates four to five years after matriculation into a cohort program. 


\section{Conclusion}

With an adequate supply of scientists and engineers, the United States would retain successful companies, spawn new ventures, and create meaningful jobs with comfortable wages. The experienced engineering educator preparation program proposed here, the Ed.D. in Engineering Education, would positively contribute to maintaining global leadership in engineering and engineering education by the United States. The potential is too valuable to waste.

Bibliography

Angelo, T. \& Cross, K. P., (1993). Classroom assessment techniques: A handbook for college teachers. San Francisco: Jossey-Bass.

Bee, H. L., (1996). The journey of adulthood, ( ${ }^{\text {rd }}$. edition). Upper Saddle River, NJ: Prentice-Hall.

Bennett, R. J., (2003). The talent gap. (paper in preparation)

Boyer, E. L., (1990). Scholarship reconsidered: Priorities of the professoriate. The Carnegie Foundation for the Advancement of Teaching. Princeton, NJ: Princeton Univerisity Press.

Brookfield, S., (1990). The skillful teacher. San Francisco: Jossey-Bass.

Brookfield, S., (1995). Becoming a critically reflective teacher. San Francisco: Jossey-Bass.

Brookfield, S, \& Preskill, S., (1999). Discussion as a way of teaching: Tools and techniques for democratic classrooms. San Francisco: Jossey-Bass.

Cranton, P., (1994). Understanding and promoting transformative learning: A guide to educators of adults. San Francisco: Jossey-Bass.

Coles, R., (1970). Erik Erikson: The growth of his work. Boston: Little, Brown.

Erikson, E., (1968). Identity: Youth and crisis. New York: Norton.

Fink, L. D., (2003). Creating significant learning experiences: An integrated approach to creating college courses. San Francisco: Jossey-Bass.

Halpern, D., \& Associates, (1994). Changing college classrooms: New teaching and learning strategies for an increasingly complex world. San Francisco: Jossey-Bass.

Hansen, S. L., (1997). Integrative life planning-Critical tasks for career development and changing life patterns. San Francisco: Jossey-Bass.

Jonassen, D.H., (2000). Computers as mindtools for schools. Upper Saddle River, NJ: Merrill Prentice-Hall.

Knowles, M., (1986). Using learning contracts. San Francisco: Jossey-Bass.

Lachman, M.E., ed. (2001). Handbook of midlife development. New York: Wiley.

Merriam, S., \& Caffarella, R. (1999). Learning in adulthood: A comprehensive guide. San Franciso: Jossey-Bass.

Miller, Patricia H., (1989). Theories of developmental psychology, $2^{\text {nd }}$. Ed. New York: W.H. Freeman and Company.

Niles, S., \& Harris-Bowlsbey, J., eds. (2002). Career development interventions in the $21^{\text {st }}$.century. Upper Saddle River, NJ: Merrill Prentice-Hall.

Schlein, S., ed. (1987). A way of looking at things: Selected papers from 1930 to 1980. Erik Erikson. New York: Norton.

Schön, D. A., (1987). Educating the reflective practitioner. San Francisco: Jossey-Bass.

Simonsen, P., (1997). Promoting a development culture in your organization: Using career development as a change agent. Palo Alto: Davies-Black.

Super, D. E., (1980). A life-span, life space approach to career development. Journal of Vocational Behavior, 16, 282-298.

Tierney, W. (ed.), (1991). Culture and ideology in higher education: Advancing a critical agenda. New York: Praeger. 
Biographical Information

EUGENE AUDETTE is Professor of Organization Learning \& Development and Associate Academic Dean of the School of Education at the University of St. Thomas. Also, he is a licensed, practicing psychologist serving business, government and nonprofit organizations. An expert on adult learning and organization development, Audette is an advocate for lifelong learning and career development. He has served on numerous boards, including the Minnesota Career Development Association, Minnesota Association for Counseling and Development and the Academy of Human Resource Development.

RONALD J. BENNETT is Director and Chair of the Engineering Programs at the University of St. Thomas. He holds a Ph.D. in Metallurgical Engineering and an MBA. With a background of 20 years in industry, Bennett teaches and publishes on diverse topics including materials engineering, technical innovation, technology transfer and engineering education. $\mathrm{He}$ is an EAC of ABET program evaluator and is currently Chair of the Graduate Studies Division of ASEE. 